\title{
O MODELO DE RACIONALIDADE COMO UMA HERANÇA DO PENSAMENTO MODERNO: UMA CRÍTICA À LUZ DA NOVA RETÓRICA
}

\section{EDUARDO CHAGAS OLIVEIRA ${ }^{1}$}

\begin{abstract}
RESUMO: A partir de uma crítica ao modelo de racionalidade edificado pelos pensadores modernos, encontra-se um ponto de convergência entre teorias empiristas e racionalistas, no que se refere ao abandono de critérios de validação do conhecimento associados à argumentação e às estruturas não-formais de raciocínio. Considerando que existe uma marca indelével na construção do pensamento acadêmico-científico, que se traduz como uma herança deixada pelo racionalismo cartesiano, Perelman sugere uma proposta metodológica argumentativa, compatível com a ideia de razoabilidade, em substituição às provas demonstrativas, mais adequadas ao campo das ciências formais, inspiradas no modelo analítico. O texto resgata ideias de filósofos modernos e antigos - como Descartes, Hume, Hobbes, Aristóteles e Platão - situando as suas teorias no projeto de construção de uma metodologia de investigação compatível com o campo das Humanidades, que inclui as Ciências Humanas e as Sociais Aplicadas, através da proposta de uma lógica do razoável, de Luis Recaséns Siches, que serviu de inspiração para a sustentação da vertente belga da Teoria da Argumentação, designada como Nova Retórica.
\end{abstract}

PALAVRAS-CHAVE: Filosofia; Modernidade; Racionalismo; Argumentação; Retórica.

ABSTRACT: From a rationality model's critique elaborated by modern thinkers, there's a convergence point between empiricist and rationalist theories about the abandonment of argumentative validation methods and non-formal reasoning structures. Considering an indelible mark of the academic-scientific thinking, the inheritance of Cartesian rationalism, Perelman proposes an argumentative method compatible with the idea of reasonability in replace of the demonstrative evidence, appropriate to the formal sciences, inspired by the analytical model. The text rescues ideas from modern and ancient philosophers - Descartes, Hume, Hobbes, Aristotle and Plato - using their theories to build an investigation method compatible with Social Sciences and Humanities, with the help of a reasonable logic, by Luis Recaséns Siches, which served for the support of the Belgian Theory of Argumentation, designated as New Rhetoric.

KEYWORDS: Philosophy; Modernity; Rationalism; Argumentation; Rhetoric.

\footnotetext{
${ }^{1}$ Professor Titular da Universidade Estadual de Feira de Santana (UEFS), pertence ao corpo docente do Progama de Pós-Graduação em Difusão do Conhecimento (FACED/UFBA) e do Programa de Pós-Graduação em Ensino, Filosofia e História das Ciências (UFBA/UEFS). Doutor em Filosofia pela Universidade Estadual de Campinas (UNICAMP). E-mail: echagas@uefs.br.
} 
Raciocinar, segundo o racionalismo herdeiro de Descartes, é demonstrar. Mas, conforme essa linha de pensamento, fundamentar racionalmente com o objetivo de sustentar normas de ação, de justificar uma atitude ou um ideal, corresponde a uma espécie de irracionalismo. Em contrapartida, para os seguidores da Escola de Bruxelas, renunciar à razão demonstrativa e ao mundo absurdo a que ela conduz, permite fazer jus a uma autêntica razão. Ocorre que, a partir do século XVII, com a visibilidade das teorias edificadas por Galileu, Descartes e Hobbes, o prestígio das provas matemáticas conduziu os filósofos à rejeição da argumentação e das estruturas não-formais de raciocínio. ${ }^{2}$ Em outras palavras, apesar das críticas que recaem sobre Descartes e os racionalistas,

Entre os modernos, não apenas os racionalistas tinham uma visão restrita da racionalidade. Também os empiristas, partidários das ciências experimentais e indutivas, tinham uma racionalidade baseada em evidências. $\mathrm{O}$ verdadeiro era o conforme aos fatos. A evidência não estava na intuição racional, mas na intuição sensível. ${ }^{3}$

Essa mudança de perspectiva, que se inicia na modernidade e se consolida gradualmente ao longo de três ou quatro séculos, estruturou um modelo de pensamento cujos resquícios ainda se mantêm vivos nos dias atuais. Antes de 1620, especialmente na França, um dos filósofos mais admirados foi o pioneiro na arte do ensaio, Michel de Montaigne. Seus escritos refletem elementos da experiência diária, diante dos quais, quaisquer seres humanos podem se reconhecer. De modo análogo a Francis Bacon, que o sucedeu, Montaigne escreveu ensaios coloquiais sobre questões tipicamente humanas, associadas à nossa experiência comum ${ }^{4}$. Diante desse quadro, pensadores de expressiva envergadura intelectual, a exemplo de Descartes e Pascal, que se opuseram às ideias de Montaigne, entenderam ser imprescindível desenvolver uma metodologia incontestável para a construção de certezas, imunizando o investigador de quaisquer resquícios remanescentes da imprecisão.

Em virtude da sua formação lógica, o filósofo polonês radicado na Bélgica, Chaïm Perelman, inspirou-se nas convicções e pressupostos do pensamento moderno, em especial do racionalismo, sobretudo no que tange à ideia de que a prova demonstrativa é o raciocínio por excelência. Em vista da incompatibilidade deste pensamento com a sua intenção de justificar as ações humanas por meio da razão - nos moldes da ideia de racionalidade que ele

\footnotetext{
${ }^{2}$ Cf. TOULMIN, 2001, p.14.

${ }^{3}$ FERES; ALVES, 2001, p.290.

${ }^{4}$ Cf. TOULMIN, 2001, p.22.
} 
compartilhava - sentiu-se compelido a romper com o seu ponto de partida racionalista, uma vez que percebeu as consequências da aplicação do raciocínio demonstrativo às condutas humanas. Contudo, ele não abandona o raciocínio demonstrativo para cair no vazio. Pelo contrário, busca amparar-se numa forma de racionalidade mais original, humana, autêntica e limitada porquanto o raciocínio demonstrativo tem uma pretensão à universalidade, porque aplicável a qualquer situação imaginável. Não obstante, verifica que o fetiche de uma razão universal, impõe o desprezo às singularidades e impede uma avaliação das situações concretas que emergem do cotidiano.

Esse afastamento dos conteúdos axiológicos, que integram o escopo de uma Lógica dos juízos de valor, exige a renúncia de Perelman ao tradicional modelo de racionalidade. Essa mudança implica aderir a algo que acontece fora do campo filosófico, sobretudo na esfera das Ciências Sociais, e de alguma forma integra o escopo de investigação da Filosofia. De Mill a Feyerabend ${ }^{5}$, vários autores buscaram uma sustentação racional para as suas teorias. No entanto, conforme os filósofos começaram a interessar-se pelo que havia se formado em diferentes áreas de conhecimento, no tocante à concepção de racionalidade, percebeu-se que era necessário haver uma harmonização conceitual, pois a expressão designava coisas bastante heterogêneas, ignorando, por vezes, o que autores clássicos da história da Filosofia já haviam apresentado acerca deste problema. É possível, inclusive, que esta mesma reação crítica recaia sobre Perelman, que também efetua uma abordagem vinculando a questão da racionalidade à(s) teoria(s) da ação, sem mencionar os aspectos epistemológicos envolvidos numa discussão que perpassa o projeto de uma teoria da argumentação, a saber: a existência de uma racionalidade específica que se exerce nas práticas humanas.

O pensamento moderno, segundo Perelman, está sob a égide do racionalismo porque permanece ligado à ideia de que a demonstração - associada ao monológico, necessário e constringente - é o raciocínio por excelência. Esse entendimento reducionista, que justifica a ênfase concedida pelos modernos a um modelo de racionalidade, descaracteriza a inspiração aristotélica que dicotomiza a razão - e, por conseguinte, os tipos de raciocínios - em classes distintas, que contemplam objetivos bem diferentes.

[O] raciocínio dedutivo é um discurso no qual, dadas certas premissas, alguma conclusão decorre delas necessariamente, diferente dessas premissas, mas nelas fundamentada. Quando o raciocínio resulta de proposições primordiais e verdadeiras ou de princípios cognitivos derivados de proposições primordiais e verdadeiras, diz-

\footnotetext{
${ }^{5}$ Principalmente no campo das Ciências Sociais, o tema da Racionalidade encontrou boa acolhida. Inicialmente a Economia, por John Stuart Mill, passando pela teoria sociológica da ação de Max Weber, na etnologia de Winch, pela Teoria das explicações racionais, pela metodologia das Ciências Sociais e, por fim, as teorias de Popper e Feyerabend que discutiam questões relativas ao problema da racionalidade. (Cf. BURGOS, 2003, p. 93-100).
} 
se que temos uma demonstração; ao raciocínio obtido a partir de proposições geralmente aceites chama-se silogismo dialético. ${ }^{6}$

Ainda que corresponda a um tipo de raciocínio monológico e necessário, a demonstração representa o autêntico modo de obtenção do que se pode designar como prova lógica. Como se depreende da observação prevista no pensamento de Aristóteles, esta redução dos raciocínios lógicos implica subdimensionamento da própria Lógica, que fica restrita ao exame da prova demonstrativa. Deste modo, a sua aceitação como modelo das formas de raciocínio, dos modos da prova lógica, se traduz na cristalização da demonstração como norma de qualquer raciocínio que pretende se impor como rigoroso. Outrossim, cumpre destacar que faz parte do imaginário ocidental, devidamente integrado ao senso comum, que existem dois tipos de razões:

\begin{abstract}
As razões teóricas, que visam aquilo que é razoável acreditar, e a razão prática, que visa o que é razoável fazer. Mas penso que uma parte essencial da concepção ocidental de racionalidade, razão, lógica, justificação, demonstração, etc., é a de que, por si mesmas, elas não nos dizem em que acreditar nem o que fazer. De acordo com a concepção ocidental, a racionalidade fornece-nos um conjunto de modos de proceder, métodos, padrões e cânones que nos permitem avaliar várias afirmações à luz de afirmações concorrentes. Nesta perspectiva, a concepção ocidental de lógica é central. A lógica não nos diz, por si mesma, aquilo em que acreditar. Só nos diz o que tem de ser o caso, dada a verdade dos nossos pressupostos e, portanto, o que estamos comprometidos a acreditar dado que acreditamos nesses pressupostos. A lógica e a racionalidade fornecem padrões de demonstração, validade e razoabilidade; mas os padrões só operam sobre um conjunto previamente dado de axiomas, pressupostos, fins e objetivos. A racionalidade, enquanto tal, não faz afirmações substantivas. ${ }^{7}$
\end{abstract}

A demonstração, assim, converte-se no ideal de prova lógica que se pretenda convincente. Esta redução da Lógica ao estudo das demonstrações, traz consigo uma redução da argumentação (não-demonstrativa) a uma mera técnica que visa assegurar a persuasão. Essas reduções, por conseguinte, provocam uma limitação da retórica ao estudo dos discursos nãodemonstrativos, alheios à Lógica ou ao uso da razão, quer seja pelo exame da argumentação como arte da eloquência, quer pelo exame das técnicas de ornamentação dos discursos.

Como romper, então, com a concepção moderna de razão, estritamente vinculada à demonstração? Perelman procura estender o uso da razão ao campo da argumentação (nãodemonstrativa), ou seja, procura um meio de ajustar a Lógica ao estudo das provas que Aristóteles chamava dialéticas.

(...) ao raciocínio obtido a partir de proposições geralmente aceites chama-se silogismo dialético. São verdadeiras e primordiais aquelas proposições que merecem crédito, não por recurso a outras proposições, mas sim por si mesmas (pois no que

\footnotetext{
${ }^{6}$ ARISTÓTELES, 2007, p.233, 100a.

${ }^{7}$ SEARLE, 1999, p.14.
} 
respeita aos princípios científicos não é pertinente perguntar porque são credíveis, uma vez que cada um desses princípios em si e por si deve ser credível); são fundadas na opinião comum aquelas proposições que parecem credíveis a todos, ou à maioria, ou aos sábios; ou ainda, de entre estes, a todos, à maioria ou aos mais conhecedores e reputados ${ }^{8}$.

Com isso, acredita consolidar uma razão argumentativa, não-demonstrativa, mas necessária para o campo da retórica, que trata da análise dos discursos não-demonstrativos, mas dotados de uma racionalidade prática, que se exerce nas práticas humanas. Por intermédio de uma razão argumentativa, Perelman pretende romper com a tradição dos modernos, pregando uma reabilitação da Retórica e, de certa maneira, promovendo um retorno aos antigos, visto que a vertente belga da teoria da argumentação restabelece uma ligação com a tradição retórica da antiguidade greco-romana, como se percebe notadamente por meio das obras de Platão, Aristóteles, Cícero e Quintiliano.

Trata-se, pois, de uma ruptura com a herança cartesiana e um resgate dos antigos, sob a forma de reabilitação da retórica, através de um reconhecimento da razão argumentativa. Essa ideia de ruptura com os modernos, entretanto, requer um esclarecimento. O posicionamento de Perelman pode ser visto como uma ruptura com o racionalismo cartesiano, pois a redução da razão à demonstração domina o pensamento moderno. Afinal, embora seja reivindicada pelos cartesianos, também se expressa por Hobbes e pelos empiristas, persistindo pelo século XIX com o entendimento de que uma tese verdadeira precisa ser - empiricamente ou racionalmente - evidente.

Em outras palavras, uma tese precisa ser demonstrada por deduções necessárias, a partir de teses evidentes, pela necessidade do movimento dialético ou, ainda, por meio de deduções decorrentes de sinais operados em sequências de signos construídos por convenção. A reabilitação da retórica, proposta por Perelman, originalmente segue dois caminhos: (1) pela ruptura com a concepção moderna da verdade, fundamentalmente cartesiana; (2) através do estudo da argumentação, como um meio de prova que não reside na evidência, empírica ou racional, tampouco em dedução necessária ou constringente. A noção de demonstração como raciocínio hipotético-dedutivo, à qual Perelman faz referência, apresenta-se por meio das ideias de Platão na seguinte passagem d' A República:

Suponho que sabes que aqueles que se ocupam da geometria, da aritmética e das ciências desse gênero, admitem o par e o ímpar, as figuras, três espécies de ângulos e outras doutrinas irmãs destas, segundo o campo de cada um. Estas coisas dão-nas por sabidas, e, quando as usam como hipóteses, não acham que ainda seja necessário prestar contas disto a si mesmos nem aos outros, uma vez que são evidentes para

\footnotetext{
${ }^{8}$ ARISTÓTELES, 2007, p.233-234, 100b.
} 
todos. E, partindo daí e analisando todas as fases, e tirando as consequências, atingem o ponto cuja investigação se tinham abalançado. ${ }^{9}$

De acordo com esta apresentação do raciocínio matemático, a demonstração é caracterizada essencialmente por ser um método específico, levado a efeito por ciências como geometria, aritmética e disciplinas análogas, que supõem como as coisas são conhecidas e se mostram intrinsecamente circulares. Seguindo esse entendimento, uma tese se revela verdadeira quando se deduz a partir de hipóteses; sendo que estas são escolhidas por aqueles que demonstram e conforme o que procuram, de modo que a tese demonstrada, no fim das contas, é tomada como ponto de partida da sua investigação. Mas, em que medida o pensamento moderno quebra com esta concepção platônica de demonstração? A tradição moderna, cartesiana, rompe com a concepção grega, platônica e aristotélica, na medida em que tende a estabelecer três princípios: (1) a universalidade do método demonstrativo, (2) a simplicidade do fundamental, (3) a unidade sistemática do saber humano. A universalidade do método demonstrativo é afirmada por Descartes sem quaisquer reservas:

\footnotetext{
Essas longas cadeias de razões, todas simples e fáceis, de que os geômetras costumam servir-se para chegar às suas mais difíceis demonstrações, haviam-me dado ocasião de imaginar que todas as coisas possíveis de cair sob o conhecimento dos homens seguem-se umas às outras da mesma maneira e que, contanto que nos abstenhamos somente de aceitar por verdadeira qualquer que não o seja, e que guardemos sempre a ordem necessária para deduzi-las umas das outras, não pode haver quaisquer tão afastadas a que não se chegue por fim, nem tão ocultas que não se descubram. ${ }^{10}$
}

O racionalismo dogmático, herdeiro do pensamento moderno, mostra-se propenso a considerar que não pode haver desacordo entre decisões racionalmente fundadas. Nesta perspectiva, "caso duas pessoas discordem, pelo menos uma delas tem de estar errada". ${ }^{11}$ Neste caso, o desacordo sobre um mesmo assunto, significa que pelos menos uma das decisões é irracional. Duas razões podem ser apresentadas para justificar este posicionamento. A primeira delas defende que a decisão equivocada decorre do conhecimento imperfeito dos fatos; a segunda, por sua vez, sustenta que ela - a decisão - resulta de motivações não racionais, como

\footnotetext{
${ }^{9}$ PLATÃO, 1980,510 c-d, p. 314-315.

${ }^{10}$ DESCARTES, 1979, p.38-39.

${ }^{11}$ Diz Descartes: "De cada vez que dois homens fazem sobre uma mesma coisa um juízo contrário, é certo que um dos dois se engana. Mas há mais, nenhum dos dois possui a verdade; porque se tivesse uma visão clara e distinta, podê-la-ia expor ao seu adversário de tal modo que acabaria por forçar a sua convicção”. (DESCARTES, 1826, p.205-206, apud. PERELMAN; OLBRECHTS-TYTECA, 1999, p. 2.
} 
a paixão, o interesse, o capricho etc. Descartes, em suas Regras para a direção do Espírito ${ }^{12}$, adota uma postura ainda mais radical; identifica o desacordo com a falta de racionalidade e acrescenta que "se dois homens exprimem juízos contrários sobre a mesma matéria, no limite, nenhum deles possui a verdade porque, se algum deles estivesse na sua posse haveria de ser capaz de convencer o outro do seu erro pondo fim ao conflito" ${ }^{13}$. Essa atitude, supostamente dirimente, caracteriza-se por considerar o desacordo uma nódoa indelével, um sinal de irracionalidade. Segundo Perelman, tal postura possui efeitos perniciosos na formação cultural do Ocidente, sendo parcialmente responsável pelo descrédito da Retórica, por exemplo, tendo em vista que impossibilita a discussão crítica de ideias, essencial ao pensamento filosófico, promovendo a paralisação da discussão racional de pontos de vista divergentes. Essa é a razão pela qual Perelman recusa "o recurso a ideias intemporais e universais, tais como a verdade, a razão e a evidência que permitem dispensar a adesão efetiva dos ouvintes". ${ }^{14}$

A oposição de Perelman ao pensamento cartesiano segue o raciocínio de David Hume, que, no Tratado da natureza humana ${ }^{15}$, opõe-se à tese da unicidade da razão, introduzindo a distinção entre juízos relativos àquilo que é (susceptíveis de verdade e falsidade) e juízos relativos àquilo que deve ser (expressão de reações emotivas e subjetivas). Nesses termos, a razão pode ser competente para distinguir a verdade do erro, mas não é suficientemente competente no que tange à apreciação de normas e valores, visto que não dispõe de um critério racional para esse fim. Desta forma, Hume conserva a insolubilidade do desacordo, pois a razão, apesar de fazer luz sobre os atos humanos, não dispõe de critérios que permitam justificar as nossas escolhas e decisões, tampouco avaliar os nossos atos e servir de guia para nossas ações. Hume com o seu cepticismo positivista e acentuadamente niilista não seria capaz de dissolver o problema que aflige Perelman por meio desta teoria, uma vez que supõe não existir verdade

\footnotetext{
${ }^{12}$ Trata-se de um opúsculo incompleto de Descartes. Os estudiosos discutem a data em que terão sido redigidas as Regulae ad Directionem Ingenii. As várias opiniões situam a sua redação entre 1620 e 1635, tendo em conta algumas alusões biográficas nas Regras 2, 4, 10. Segundo H. Gouhier, as Regras não devem ser anteriores a 1623; constituiriam uma espécie de resultado do trabalho intelectual feito entre 1623 e 1628 e foi neste último ano que Descartes as teria posto por escrito. Por seu turno, a história física do texto tem alguns meandros. Há três manuscritos importantes: a) o manuscrito original, que pertencia a Clerselier, mas perdeu-se; b) uma cópia que foi de Leibniz e se encontrou na biblioteca de Hanôver; e c) a cópia de que se serviram os editores dos Opuscula posthuma na primeira edição do texto latino em Amsterdã (1701), e que também desapareceu. Charles Adam (e Paul Tannery), na sua grande edição dos escritos cartesianos, Oeuvres de Descartes (Paris: Cerf, 1908), atualmente editados pela Vrin), recorreu ao texto publicado nos Opuscula e às variantes do manuscrito de Hanôver. (MORÃO, 1989)

${ }^{13}$ Para Descartes, o desacordo era impossível de ser aceito porque representava o mais óbvio dos sinais de erro. Considerando-se, entretanto, que o desacordo é o campo de eleição da retórica, ao menos da sua vertente argumentativa, contrariamente ao que pretendia Descartes, Perelman tenta retoricamente pensar a possibilidade de soluções diferentes sem que o desacordo seja inevitável.

${ }^{14}$ PERELMAN, 1997, p. 181.

${ }^{15}$ HUME, David. Tratado da Natureza Humana. São Paulo: UNESP, 2001.
} 
ou critério racional - em matéria de avaliação de normas e valores - associados à justificação da ação humana. Este posicionamento não é distinto do constrangimento legado pelo dogmatismo racionalista a uma filosofia moral, que acredita na objetividade das regras de conduta e na possibilidade de obtermos para cada caso a solução objetivamente melhor. ${ }^{16}$ Perelman esforça-se para justificar o desacordo entre proposições racionalmente fundadas, propondo como ilustração desse entendimento a tradição judaico-talmúdica, que consente a razoabilidade simultânea das razões expressas em teses opostas, desde que fundamentadas a partir da interpretação da Bíblia. No mesmo sentido encontra-se a proposta de Winch, expressa num artigo intitulado Universalizability of Moral Jugements, onde se infere que "dois juízos morais diametralmente opostos sobre um mesmo problema concreto podem ser ambos respeitáveis e razoáveis". ${ }^{17}$

O desacordo poderá ter a sua origem apenas no fato de as pessoas terem avaliado de modo diferente uma circunstância particular, qualquer que seja ela, atribuindo-lhe uma importância relativa distinta. Isso é suficiente para que tais pessoas, adotando razões igualmente objetivas, decidam de modo diferente sobre o mesmo assunto. Dever-se-á considerar imparcial, então, uma decisão na qual a pessoa assume o seu posicionamento como critério para eventos futuros, com o fito de aplicar-lhe a todas as situações essencialmente semelhantes, independendo de quem possam ser os destinatários da sua decisão. No entanto, sempre que alguém decida razoavelmente acerca do que é moralmente justo para si, não tem legitimidade para supor que estabeleceu o critério de razoabilidade para futuras decisões de outrem, uma vez que a justiça de uma decisão não fica indelevelmente marcada pela necessidade e constringência lógica, que afeta a verdade de uma proposição. ${ }^{18} \mathrm{O}$ precedente judiciário, sob este aspecto, será apenas uma ancoragem exigida pelos imperativos da segurança e da coerência. Algumas vezes, torna-se necessário estabelecer, por razões de ordem prática, uma linha de conduta uniforme, visando ultrapassar o limiar em que um mesmo estado de coisas pode ser razoavelmente justificado por juízos de valor diferentes. Sempre que o desacordo acontece em sede de um tribunal coletivo, por exemplo, o critério de decisão por maioria pode ser reconhecido como critério que se justifica por razões de oportunidade. Isso nos conduz a pensar sobre os conceitos

\footnotetext{
${ }^{16}$ Esta marca da objetivação em Filosofia Moral está presente em Methods of Ethics, de Sidgwick (1907), que formula a sua "máxima da justiça e equidade". M.G.Singer, inclusive, utiliza de critérios análogos para desenvolver o "princípio de generalização", que ele reconhece associado à Regra de Justiça, de Perelman, e à máxima de justiça e equidade, de Sidgwick.

${ }^{17}$ WINCH, 1972.

${ }^{18}$ Cf. PERELMAN, 1996, p.3-ss.
} 
de racionalidade e razoabilidade, sua desconexão com o pensamento moderno e a construção de uma racionalidade argumentativa.

O conceito de razoabilidade ou de razoável e, por conseguinte, sua respectiva antonímia, é de importância fundamental para a teoria da racionalidade argumentativa de Perelman, mostrando-se esclarecedor à compreensão da sua oposição ao pensamento moderno. $\mathrm{O}$ problema é que a ideia de razoável às vezes aparece como uma noção de caráter geral, aplicável a qualquer tipo de argumentação, embora também se apresente como uma noção especifica, como um conceito que cobra importância em certos tipos de argumentações, tal como no caso da argumentação jurídica, por exemplo. Nesses casos, a questão da argumentação se alinha a um problema hermenêutico. Deve-se salientar que, neste caso especificamente, não são razoáveis as noções, mas o procedimento aplicado na interpretação delas. Por isso mesmo,

\footnotetext{
A vaguidão de certos conceitos termos, que figuram num texto legal ou regulamentar, dá latitude ao intérprete, mas, a não ser que se considerem certas expressões, tais como "interesse comum", "urgência" ou "equidade" como expressões vazias, há limites para o poder de apreciação. ${ }^{19}$
}

O conceito de razoabilidade ou de razoável, enquanto conceito específico, é designado muitas vezes com o uso de outras expressões como "trato equitativo", "igualdade" ou “discriminação”, que são noções confusas por excelência. Generalizando ainda mais, poder-seia dizer que a noção de razoabilidade é um componente comum que se costuma chamar, com 
frequência, de "conceitos jurídicos indeterminados". ${ }^{20}$ Seria, então, o conceito de razoabilidade um dos conceitos aos quais Perelman designou como noções confusas? Ainda que extrapolem o campo da aplicação da justiça, os conceitos jurídicos indeterminados são noções que refletem o resultado da utilização, em campos distintos, de um mesmo conceito básico: o de razoabilidade. No entanto, mesmo que se trate de uma noção variável, não implica que seja também uma noção confusa porque, para Perelman, o razoável tem um limite que vem marcado pelo auditório. O problema é que esta última noção, embora seja central para a concepção perelmaniana de argumentação, é muito "escorregadiça". ${ }^{21}$ Além disso, a noção de auditório ou, mais especificamente, do acordo do auditório, que demarca o limite do aceitável ou do razoável, padece, na obra de Perelman, de uma certa ambiguidade. Por um lado, configura-se como um acordo ou um consenso ideal e, por outro lado, parece estar ligado a fatos contingentes de caráter social e cultural. Outra dificuldade do conceito repousa em sua escassa potencialidade crítica, porque pressupõe-se que, diante de um mesmo caso, pode-se tomar diversas decisões que (respeitados certos limites, que parecem configurar-se de maneira bastante clara) haveria de se considerar como aceitáveis e, portanto, como igualmente justificáveis. ${ }^{22}$ Outrossim, a vinculação da noção de razoabilidade com a ideia de auditório permite considerar irrazoável tudo aquilo que é considerado inadmissível em uma comunidade em determinado contexto,

\footnotetext{
${ }^{20}$ Os conceitos jurídicos indeterminados são assim chamados porque seu conteúdo é menos preciso que o dos conceitos jurídicos determinados (exemplo destes, os numéricos 18 anos, 24 horas , daqueles, "casa particular"). Os conceitos jurídicos indeterminados podem ser descritivos (ex. patrimônio, cobrança) ou normativos (ex. justa causa, boa-fé) (cf. ENGISCH, 1988, p. 210). Os normativos exigem valoração. No caso da dignidade humana, o conceito, além de normativo, é axiológico porque a dignidade humana é valor a dignidade é a expressão do valor da pessoa humana. Todo "valor" é a projeção de um bem para alguém; no caso, a pessoa humana é o bem e a dignidade, o seu valor, isto é, a sua projeção. Princípio jurídico, por sua vez, é a idei diretora de uma regulamentação (cf. LARENZ, 1985, p. 32). O princípio jurídico não é regra, mas é norma jurídica; exige não somente interpretação, mas também concretização. Desta forma, pode-se contrapor os conceitos jurídicos determinados aos conceitos jurídicos indeterminados. Aqueles delimitam a realidade à qual se referem de maneira precisa e inequívoca, ou ao menos possibilitam certa precisão quando inseridos em um contexto, enquanto estes possuem um grau de indeterminação que dificulta a apreensão de seu conteúdo. De maneira mais aprofundada, Marcelo Harger ensina que os conceitos indeterminados "são dotados de um grau de indeterminação bastante elevado, o que dificulta a apreensão de seu conteúdo. Apesar de procurarem delimitar a realidade, eles não o conseguem, a não ser dentro de limites bastante amplos, pois não podem ser quantificados ou determinados rigorosamente" (HARGER, 1998, p. 11). Apesar de não delimitarem seu significado com precisão, os conceitos indeterminados apresentam um campo significativo mínimo. Desta forma, a existência de indeterminação em um conceito não significa que inexistam meios para suprimi-la ou reduzi-la. Isto porque "todo conceito indeterminado é finito, uma vez que as palavras têm um conteúdo mínimo, sem o qual a comunicação seria impossível." (Cf. ENGISCH, Karl. Op. Cit, p.170-221).

${ }^{21}$ Sempre que há a impossibilidade argumentativa de sustentar uma teoria, Perelman recorre à noção de auditório. Isso ocorre com o conceito de noções confusas, com a distinção entre convencer e persuadir, bem como no tratamento da noção de razoabilidade. Em qualquer dos casos, Perelman deixa margem à contestação pela fragilidade da própria noção de auditório universal que, por vezes, é associada à ideia dos universais lógicos e, por outras, a uma noção de imperativo da razão.

${ }^{22}$ Conforme o conceito de regra de justiça, apresentado no Da Justiça (1945) e reproduzido em Ética e Direito (PERELMAN, 1996, p.85-ss).
} 
motivo pelo qual "o razoável não remete a uma solução única, e sim implica uma pluralidade de soluções possíveis; porém, há um limite para essa tolerância, e é o desarrazoado que não é aceitável." ${ }^{23}$ Neste excerto, por exemplo, Perelman faz uso do conceito aplicando-o no campo jurídico:

\begin{abstract}
Enquanto, em Direito, as ideias de razão e de racionalidade foram vinculadas, de um lado, a um modelo divino, do outro à lógica e à técnica eficaz, as do razoável e de seu oposto, o desarrazoado, são ligadas às reações do meio social e à evolução destas. Enquanto as noções de "razão" e de "racionalidade" se reportam a critérios bem conhecidos da tradição filosófica, tais como as ideias de verdade, de coerência e de eficácia, o razoável e o desarrazoado são ligados a uma margem de apreciação admissível e ao que, indo além dos limites permitidos, parece socialmente inaceitável. ${ }^{24}$
\end{abstract}

As noções de razoável e de desarrazoado apresentadas por Perelman foram bastante utilizadas na obra do jurista espanhol Luís Recaséns Siches, responsável pelo desenvolvimento de uma Lógica do razoável ${ }^{25}$, na década de 1950. Para Siches, a insuficiência ou inadequação da Lógica tradicional, da lógica físico-matemática ou do modelo racional para tratar de problemas práticos, como os da interpretação do Direito ou da Filosofia, exigia o desenvolvimento de uma outra Lógica, capaz de fornecer ferramentas para tratar de problemas de natureza prática. Em sua opinião,

La lógica formal (...) no agota ni remotamente la totalidad del logos, de la Razón, sino que es tan sólo una provincia o un sector (...). Aparte de la lógica de lo racional, aparte de la lógica formal de la inferencia, hay otras regiones que pertenecen igualmente al logos, pero que son de índole muy diversa de aquella lógica de lo racional en sentido estricto. Entre esas otras zonas o regiones (...), figura el ámbito del logos de los problemas humanos de conducta práctica, al que yo he llamado logos de lo razonable. ${ }^{26}$

O fato de que nos problemas jurídicos e nos problemas de interpretação, em particular, não se possa utilizar a lógica formal não implicaria, pois, um afastamento da lógica, mas a utilização de uma lógica distinta: a lógica do humano ou do razoável, que é uma lógica material, uma lógica dos conteúdos. Parece que o conceito de "razoável” (ou do logos do razoável) não chega a ter, na obra de Recaséns Siches, um grau elevado de elaboração teórica. A

\footnotetext{
${ }^{23}$ PERELMAN, 1996, p. 432.

${ }^{24}$ PERELMAN, 1996, p. 436.

${ }^{25}$ A denominada Lógica do Razoável possui grande aplicação no âmbito jurídico - onde as questões de Lógica não-formal têm encontrado grande possibilidade de desenvolvimento. No âmbito da discursividade política, bem como ocorre no âmbito jurídico, por vezes, temos de nos precaver para não penetrarmos na esfera do logos meramente formal.
}

${ }^{26}$ SICHES, 1971, p. 519. 
caracterização concedida se restringe a uma série de afirmações substancialmente vagas, com as seguintes características:

[o logos do razoável] está limitado, condicionado y influido por la realidad concreta del mundo en que opera; está impregnado de valoraciones; tales valoraciones son concretas; las valoraciones constituyen la base o apoyo para la formulación de propósitos; la formulación de propósitos o establecimiento de finalidades no sólo se apoya sobre valoraciones sino que además está condicionado por las posibilidades que depare la realidad humana social concreta; el logos de lo humano está regido por razones de congruencia o adecuación entre la realidad social y los valores, entre los valores y los fines, etc; y está orientado por las enseñanzas sacadas de la experiencia vital e histórica, esto es, individual y social. ${ }^{27}$

A afirmação de que o razoável é uma noção de conteúdo variável ${ }^{28}$, ou mesmo um valor função ${ }^{29}$, deve ser entendida tanto em um sentido histórico (social), como em sentido lógico, pois aquilo a que se considera razoável está condicionado por circunstâncias espaciais e temporais (sentido histórico), bem como depende do campo em que se aplique a noção (sentido lógico), uma vez que há de se entender por razoável aquilo que, em cada caso, existe em função da aplicação do conceito. No percurso até então empreendido, a tentativa de mostrar como a noção de razoável perpassa a teoria da argumentação de Perelman parece insuficiente, se não limitada. Restaria, entretanto, indagar: como é possível sustentar uma teoria da argumentação em pilares tão frágeis como o conceito de razoabilidade, por exemplo? Podemos considerar razoável a noção de razoável proposta por Perelman? Se for possível, como sustentar o critério de razoabilidade que adotamos? Se não for, com base em quais critérios podemos refutar? Como se caracterizam os problemas para os quais a razoabilidade pode ser usada como critério, no intuito de resolvê-los?

Para elaborar uma noção que se possa ver como uma reconstrução do razoável, tal e como se utiliza na prática argumentativa, que serve de foco para a construção da teoria da argumentação de Perelman, é necessário que esta noção tenha uma certa potencialidade crítica, ou seja, é necessário que se possa utilizar como um critério ou esquema sistemático de ajuste conceitual, que ajude a justificar as razões pelas quais uma determinada interpretação ou decisão é preferível em detrimento de outra. Ora, parece crível que a noção de preferível se ajusta ao nível de elaboração conceitual de uma argumentação, donde decorre que a fundamentação de uma exposição a torna mais ou menos preferível porque melhor ou pior justificada.

\footnotetext{
${ }^{27}$ SICHES, 1971, p. 525-526.

${ }^{28}$ PERELMAN, 1978, p. 35-42.

${ }^{29}$ MACCORMICK, Neil. On Reasonableness. PERELMAN; ELST. Les Notions a Contenu variable en Droit, 1984.
} 
Seguindo o pensamento de Goblot - que também buscou estabelecer uma Lógica dos Juízos de Valor - Perelman, insatisfeito com a definição de racional a partir do critério de evidência, se predispõe a pensar em uma lógica capaz de orientar as ações humanas, ou seja, apta a lidar com valores. Seria uma lógica específica das normas, tal como a Lógica Deôntica, de Von Wright ${ }^{30}$, bastante estudada no campo jurídico e responsável por fornecer um tratamento aos modos de pensamento não-formais, como a retórica e a tópica. O interesse de Perelman está centrado na ideia de estabelecer uma forma de raciocínio - considerado lógico que embora não esteja em conformidade com os critérios da Lógica formal, não seja considerado irracional ou ilógico. Conquanto o próprio Perelman (não declaradamente), seguindo o pensamento de Edmond Goblot, denomine essa nova lógica de Lógica dos juízos de valor, trata-se de uma lógica do diálogo (dia-lógica), uma lógica do razoável e da persuasão, uma teoria da argumentação e da interpretação a que ele preferirá denominar de Nova Retórica. Mas, uma vez que Perelman, sob as mais diversas fontes de inspiração e suporte teórico, consagrou a utilização do termo retórica, pergunta-se: qual conceito ou compreensão pode corresponder a esse termo? Questionamos a possibilidade da Nova Retórica ser mais bem representada pela designação de Nova Dialética. Na segunda parte da Introdução do Tratado, inclusive, Perelman ensaia uma justificativa para sustentar a sua opção. Em suas palavras:

(...) nosso Tratado se relaciona, sobretudo com as preocupações (...) dos autores gregos e latinos, que estudaram a arte de persuadir e de convencer, a técnica da deliberação e da discussão. É por essa razão também que o apresentamos como uma nova retórica. Nossa análise [, entretanto,] concerne às provas que Aristóteles chama de dialéticas, examinadas por ele nos Tópicos, e cuja utilização mostra na Retórica. ${ }^{31}$

Esse suposto ponto de chegada proposto pelo autor, entretanto, não é senão ponto de partida, visto que, longe de fechar a discussão acerca da natureza da nomenclatura e, por conseguinte, do objeto de investigação da sua obra, só faz mantê-la aberta a questionamentos e problematizações. Seja como [Nova] Retórica ou [Nova] Dialética? É possível que a melhor resposta para esse questionamento emane de uma investigação acerca da finalidade da sua teoria.

\footnotetext{
${ }^{30}$ Von Wright (1916-2003) escreveu um paper intitulado Estudos sobre a lógica deôntica, publicado na revista Mind, no qual analisa como o legislador formula de modo abstrato as regras que organizam a sociedade. Como o legislador organiza seu discurso? Quais os fatores? Nisso se concentrou a preocupação de Von Wright. Assim, a lógica jurídica ganha autonomia porque a lógica deôntica pode dar à Jurisprudência o fundamento da dedução no domínio das normas. Portanto, a lógica jurídica só vem a nascer com sua preocupação delimitada no séc. XX, com a obra Lógica Deôntica, de Von Wright. Trata-se essa obra de um vanguardismo na discussão de como o juiz chega a construir decisões justas. (cf. VON WRIGHT, 1951, p.1-15).

${ }^{31}$ PERELMAN ; OLBRECHTS-TYTECA, 1999, p.5.
} 
A Nova Retórica tem como objeto "o estudo das técnicas discursivas que permitem provocar ou aumentar a adesão dos espíritos às teses que se lhes apresentam ao assentimento"32 e, assim sendo, sua finalidade se caracteriza pela busca de uma eficácia discursiva. Essa noção encontra amparo, aliás, em outra passagem da obra de Perelman, mais especificamente em Logique et Rhétorique, onde o autor afirma que "(...) ce que la correction est pour la grammaire, la validité pour la logique, l'efficacité l'est pour la rhétorique". ${ }^{33}$ Desta maneira, a preocupação com a eficácia discursiva permite que se desfaça qualquer conexão entre a Nova Retórica e elementos reguladores externos. A Nova Retórica se define como uma técnica e, assim sendo, é preciso conhecer e aplicar os seus meios para atingir os resultados específicos, ou seja, a adesão dos interlocutores e a anuência do auditório. Desse ponto de vista, o melhor argumento é o mais forte. A força, no sentido retórico, é vista como uma noção que está situada entre a eficácia psicológica e a validade lógica. Mas, em meio a essa situação, encontra-se um relativismo moderado, visto que não existem garantias para a eficácia do discurso. As teses que aceitamos ou defendemos não estão fundadas sobre uma verdade objetiva, mas sobre uma referência a um contexto argumentativo.

Existem, aqui, duas situações distintas que permitem compreender a finalidade da Nova Retórica e, por conseguinte, sustentar sua vinculação com a Dialética, por um lado, e com a Retórica, por outro. Se aceitarmos a hipótese de que qualquer argumentação se destina a um auditório, pois quando se argumenta, objetiva-se conquistar a adesão do seu interlocutor, a Nova Retórica está mais próxima da Retórica. Mas, se considerarmos que Aristóteles, no princípio dos Tópicos, ao fundar as bases do seu método dialético, define que seu propósito consiste em "encontrar um método de investigação graças ao qual possamos raciocinar, partindo de opiniões geralmente aceitas, sobre qualquer problema que nos seja proposto, e sejamos também capazes, quando replicamos a um argumento, de evitar dizer alguma coisa que nos cause embaraços" ${ }^{34}$, teremos a Nova Retórica mais próxima da Dialética, visto que esta última também se propõe a ser um método de raciocinar apoiando-se em ideias plausíveis. Será possível, então, desfazer ou simplesmente decifrar, esse híbrido teórico a que Perelman designa com o nome de Nova Retórica? Tentemos encontrar, em suas próprias palavras, alguns elementos que nos conduzam neste sentido. Diz Perelman:

Se, entre os antigos, a retórica se apresentava como o estudo de uma técnica para o uso do vulgo, impaciente por chegar rapidamente a conclusões, por formar uma

\footnotetext{
${ }^{32}$ L'étude des techniques discursives permettant de provoquer ou accroître l'adhésion des esprits aux thèses qu'on présente à leur assentimento. (Cf. PERELMAN; OLBRECHTS-TYTECA, 1958, p.5. A esse respeito ver também: PERELMAN, 1970, p. 105.)

${ }^{33}$ Cf. PERELMAN, 1950, p.98.

${ }^{34}$ ARISTÓTELES, 1978, 100 a 18.
} 
opinião para si, sem se dar ao trabalho prévio de uma investigação séria, quanto a nós, não queremos limitar o estudo da argumentação àquela que é adaptada a um público de ignorantes. ${ }^{35}$

Mais uma vez, ao tentar sustentar a sua teoria da argumentação como uma nova retórica, o autor aproxima a sua concepção do pensamento dialético de Aristóteles. Afinal, este último é enfático ao descrever que "o raciocínio é dialético quando parte de opiniões geralmente aceitas". ${ }^{36}$ Ora, são “opiniões 'geralmente aceitas' aquelas que todo mundo admite, ou a maioria das pessoas, ou os filósofos - em outras palavras: todos, ou a maioria, ou os mais notáveis". ${ }^{37}$ Entretanto, "não se deve argumentar com todo mundo, nem praticar argumentação com o homem da rua". ${ }^{38}$ Assim, embora o raciocínio dialético, na concepção aristotélica descrita nos Tópicos, consista no debate cru de opiniões geralmente aceitas, esse entrave dialógico somente se dá entre homens hábeis em propor questões e levantar objeções, pois não se deve praticar argumentação com qualquer pessoa. Nos dois casos, ou seja, nos Tópicos de Aristóteles e na Nova Retórica de Perelman, existe uma ressalva comum ao se propor uma seleção para que se firme um diálogo efetivo. Desta forma, as semelhanças entre a finalidade da Nova Retórica e o objeto dos Tópicos tornam possível, a fortiori, estabelecer uma vinculação mais estreita entre a teoria da argumentação e a nomenclatura que lhe poderia caber de Nova Dialética.

Uma vez que a Teoria da Argumentação, sob inspiração da Dialética ${ }^{39}$, de Aristóteles, procura encontrar a melhor opção para um tratamento teórico sistemático, com critérios e normas bem definidos para a construção de discursos, é possível que uma incursão ao sentido encontrado no pensamento antigo possa oferecer alguma contribuição para o recorte que efetuamos, visto que o fundamento do gênero de diálogo que importa à nossa pesquisa possui as suas bases na tradição que se consolidou pelo pensamento inspirado no modelo socrático-platônico. Desde a antiguidade é possível observar que o termo dialética não é utilizado pelos filósofos gregos com o mesmo significado. A natureza confusa do conceito,

\footnotetext{
35 PERELMAN; OLBRECHTS-TYTECA, 1999, p.7.

${ }^{36}$ ARISTÓTELES, 1978, 100b 18.

${ }^{37}$ ARISTÓTELES, 1978, 100b 22.

${ }^{38}$ ARISTÓTELES, 1978, 164b 10.

${ }^{39} \mathrm{O}$ sentido etimológico da expressão diálogo poderia fornecer alguma luz para a solução do nosso problema, a saber: descobrir se a Teoria da Argumentação consiste em uma Nova Retórica ou em uma Nova Dialética, visto que, do ponto de vista etimológico, o termo $\delta 1 \alpha \lambda$ o

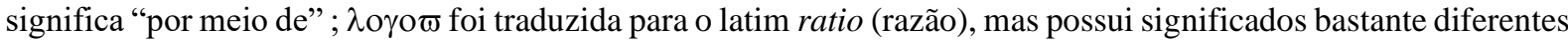
como "palavra", "expressão", "fala" e "verbo". Em uma concepção estritamente vinculada ao sentido etimológico da palavra, o Diálogo pode ser visto como uma forma de fazer circular sentidos e significados por meio de palavras, promovendo uma troca ou discussão de ideias, opiniões e conceitos, com vista à solução de problemas, ao entendimento ou à harmonia. Em um grupo que dialoga, as palavras circulam entre as pessoas, passam entre elas, sem que sejam necessárias concordâncias ou discordâncias imediatas.
} 
embora não permita uma definição, uma concepção unívoca acerca da dialética, permite um recorte bem definido que possibilite o entendimento do termo. Em virtude dos múltiplos significados que o conceito assumiu no curso da história do pensamento ocidental, Perelman destaca $^{40}$ que a noção de dialética sempre foi apreciada com certa reserva, como se pode constatar nas palavras do lógico holandês Evert Willem Beth:

\begin{abstract}
A dialética de Platão ramificou-se, logo em sua origem, em três doutrinas separadas, das quais somente uma desenvolveu-se de uma forma retilínea e contínua, de modo que atualmente apenas a lógica constitui uma construção sólida cuja importância para o pensamento científico já não poderia ser seriamente posta em dúvida. A arte de discutir e a metafísica, em contrapartida, mostram de forma manifesta as enfermidades da velhice e parecem estar condenadas a incorporar-se na Lógica. Em consequência, parece-me inoportuno tentar reintroduzir o termo "dialética" na terminologia da filosofia científica, tanto mais que tal termo foi, no palavreado de certas escolas filosóficas, associado a pretensões particularmente ambiciosas, incapazes de se realizar no campo do pensamento científico. ${ }^{41}$
\end{abstract}

As palavras de Beth sinalizam a necessidade de criar uma espécie de assepsia filosófica, extraindo do vocabulário especificamente filosófico tudo aquilo que conduz à controvérsia. $\mathrm{O}$ confuso, devido à sua inconsistência e consequente equivocidade, deve ser banido da prática filosófica, bem como tudo quanto é possível de produzir concepções pessoais, subjetivas e passíveis de serem contaminadas por juízos de valor parciais, mutáveis e contingentes. ${ }^{42}$ Esse entendimento se contrapõe à concepção de dialética, em Platão, por exemplo. A tradição platônica se constitui a partir de um procedimento dialógico através do qual o raciocínio avança gradativamente, sendo constantemente avaliado e ratificado por meio da anuência do interlocutor. Em outras palavras, cada estágio do procedimento discursivo deve ser acompanhado de uma reavaliação dos aspectos discutidos, em consonância com a aceitação do ouvinte, que deve emitir um juízo acerca do que se trata. Desta forma, as ideias precisam ser submetidas à formação conjunta de um raciocínio exigente e comprometido com o resultado que deverá corresponder à verdade.

Ainda que a dialética conduza à busca da verdade, a controvérsia é o seu combustível. Incompatibilidades e controvérsias, características da argumentação retórica, são formuladas e descartadas. ${ }^{43}$ Não se faz imperativo concordar ou discordar, mas apresentar ideias à apreciação do(s) interlocutor(es), visto que o diálogo tem como função permitir a circulação de ideias entre várias pessoas. Isso quer dizer que por meio do diálogo a palavra liga e permeia, em vez de

\footnotetext{
${ }^{40}$ PERELMAN, 1997, p.3.

${ }^{41}$ PERELMAN, 1997, p.3-4.

42 PERELMAN, 1997, p.24.

${ }^{43}$ PERELMAN, 1997, p.78.
} 
separar; agrega, em vez de fragmentar. Essa noção nos leva a perceber que a interação dialógica não é um instrumento para que as pessoas defendam e mantenham suas posições, tal como acontece na discussão e no debate. Na esfera da teoria da argumentação, qualquer diálogo implica em contextualização, audiência e eloquência, porque os argumentos estão situados em um determinado momento histórico, dirigem-se a um auditório específico e são atribuídos a um orador que, por meio do seu discurso, pretende exercer uma ação sobre o auditório. A Nova Retórica espera que os ouvintes estejam dispostos a escutar, a sofrer a ação do orador. O desejo de persuasão, por sua vez, sustenta que o orador, em vez de dar ordens ao auditório, deverá conquistar a sua adesão intelectual. Essa adesão nada tem a ver com a verdade ou falsidade das teses que o orador procura defender, mas está associada ao seu poder argumentativo [discursivo], pois o argumentar permite pressupor que é tão possível defender uma tese como o seu contrário. Para provocar a adesão do auditório a certas teses, entretanto, é fundamental que o orador conheça os valores inicialmente admitidos por esse auditório, pois eles deverão constituir o ponto de partida do discurso. ${ }^{44}$

Para conhecer os valores do auditório, por sua vez, é comum recorrer ao questionamento - é a essa técnica que Sócrates recorre nos diálogos platônicos - donde se reafirma a importância da dialética. Visando a resolução argumentativa dos entraves dialógicos, a Teoria da Argumentação propõe um tratamento racional dos conflitos de opinião. Esse é um traço específico que a afasta das concepções de retórica, visto que a Teoria da Argumentação não propõe um sistema de regras normativas para a discussão crítica. É igualmente difícil sustentar a sua aproximação com uma concepção de Lógica, tal como pretende Perelman, pois a sua teoria se apoia em noções confusas que promovem - e sofrem - mudanças argumentativas constantes. Ademais, não se propõem regras para o orador ser bem-sucedido em sua relação com o auditório. A Nova Retórica simplesmente faz uma análise dos modelos discursivos e apresenta o ideal da discussão crítica, a partir de uma análise acurada das complicações concretas do discurso argumentativo. É possível, sob este aspecto, que a designação de Nova Dialética melhor coubesse à Nova Retórica. Talvez, inclusive, tenha sido este o motivo pelo qual Eemeren e Grootendorst tenham aprofundado as questões levantadas pela Nova Retórica para constituir a Nova Dialética (Pragma-dialética). Entretanto, as especificidades desta última aproximam-na de uma reconstrução da Retórica, enquanto as características da Nova Retórica permitem-nos aproximá-la de uma reconstrução da Dialética.

44 A esse respeito conferir a detalhada referência aos pontos de partida da argumentação, no Tratado da Argumentação. (Cf. PERELMAN; OLBRECHTS-TYTECA, 1999, p. 73-130). 
A interpretação de expressões cristalizadas por seu uso e aplicação, tal como ocorre com a expressão em questão, é um assunto de considerável dificuldade, visto que, o termo costuma ser empregado, interpretado e aceito sem maiores contestações. Entretanto, tal como a própria teoria sugere, é preciso salientar que a construção de uma interpretação já carrega, consigo mesma, a certeza de sua possibilidade de contestação; ou seja, qualquer teoria, conceito ou interpretação é potencialmente contestável. Não obstante, é possível distinguir pelo menos três aplicações que buscam caracterizar a Nova Retórica: (1) Apresentando-a como uma reconstrução inerte da Retórica Antiga, mantendo-a como uma espécie de oratória digna de apreço, embora desprovida de conteúdo; (2) Caracterizando-a como uma técnica desenvolvida para a aquisição e uso persuasivo da linguagem; (3) Apontando-a como um meio de construir argumentos, por meio de um procedimento dialógico que angaria valores e crenças na composição de ideias que pretendem sustentar uma afirmação.

Michel Meyer, por exemplo, no prefácio do Tratado da Argumentação, considera que a Nova Retórica representa uma espécie de

(...) discurso do método de uma racionalidade que já não pode evitar os debates e deve, portanto, tratá-los e analisar os argumentos que governam as decisões. Já não se trata de privilegiar a univocidade da linguagem, a unicidade a priori da tese válida, mas sim de aceitar o pluralismo, tanto nos valores morais como nas opiniões. A abertura pra o múltiplo e o não coercitivo torna-se, então, a palavra mestra da racionalidade..$^{45}$

Entende-se, neste caso, a Nova Retórica como uma lógica do diálogo, cuja estrutura se forma por meio de questionamentos e opiniões emitidos acerca de um determinado problema. Nesse sentido, ela corresponde a um método filosófico de investigação, que fomenta um ambiente crítico em que prevalece a controvérsia e a especulação e no qual o trabalho filosófico, enquanto diálogo e discussão, é mediado pela anuência dos interlocutores. Esta, por sua vez, se mostra essencial porque serve de ponto de partida para a argumentação; não porque se trata de um concurso de duas opiniões destoantes, mas porque essa concordância representa a expressão de uma adesão generalizada às proposições em questão. A concordância dos interlocutores, assim, concerne àquilo que é considerado válido ou obrigatoriamente aceito, no meio em que representam, até sua contestação efetiva. Por outro lado, o ponto inicial de uma argumentação dialética não consiste em proposições necessárias, incondicionalmente válidas (independente do contexto), mas em proposições efetivamente aceitas em dado meio e que, em outro meio ou

\footnotetext{
${ }^{45}$ Cf. MEYER, Michel. Prefácio. In: PERELMAN; OLBRECHTS-TYTECA, 1999, p. XX.
} 
contexto histórico e social, poderiam não usufruir da aprovação geral ${ }^{46}$. $\mathrm{Na}$ concepção de Goblot:

\begin{abstract}
A Dialética procede mediante perguntas e respostas, para jamais passar de uma asserção para a seguinte sem se estar seguro do assentimento do interlocutor. A arte do dialético é agir de modo que esse assentimento nunca possa ser recusado. Esse método do diálogo é essencialmente oral e exige o concurso de pelo menos duas pessoas. Por que Platão pensa, entretanto, que possa ser praticado em uma obra escrita, em que a mesma pessoa, o autor, faz igualmente as perguntas e as respostas? Seu próprio assentimento dá-lhe o direito de seguir em frente? Platão pensa estar seguro de que nenhum interlocutor poderia responder de modo diferente de quem ele faz falar. Essa é toda a arte da dialética (....). ${ }^{47}$
\end{abstract}

As palavras de Goblot parecem sugerir que Platão pensa de acordo com uma suposta racionalidade universal, ou seja, ao antever a reação intelectual do seu interlocutor, Platão pensa na recepção de um auditório universal, ainda que se dirija, em diálogo, a um indivíduo particular (ou virtual). Sendo correta a interpretação de Goblot acerca da noção de dialética e, de fato, o desdobramento do diálogo sendo completamente indiferente à personalidade do interlocutor, a forma dialogada não passaria de uma adulação astuciosa, visto que o indivíduo que responde aos questionamentos em um diálogo, ao responder, somente estaria encarnando as reações de uma mente normal, perante o óbvio. Perelman discordará de Goblot, porque este ignora que "a dialética platônica constitui um esboço do sistema dedutivo" 48 num processo em que as teses decorreriam umas das outras criando uma correlação entre a Dialética e Analítica, transformando o procedimento dialético em algo tão coercivo quanto a demonstração formal. Mas, se o diálogo transcorre sem a interferência da personalidade de um interlocutor, como Perelman interpreta a afirmação de Goblot, a expressão do diálogo consiste num engodo arriscado capaz de conduzir à ideia, certamente equivocada, de que o interlocutor não desempenha qualquer papel no diálogo. Assim sendo, a dialética platônica seria um bosquejo do sistema dedutivo, por meio do qual as afirmações se sucederiam umas das outras, utilizandose de um mecanismo interno, capaz de conduzir, mecanicamente, a um procedimento conclusivo razoável, transformando o método dialético num sistema dialético integrado.

A crítica que Perelman desenvolve acerca da ideia de Goblot, sobre a Dialética, parece guardar uma contradição no tocante às suas próprias concepções. A suposta racionalidade universal a que Platão apela é bastante semelhante ao auditório universal proposto por Perelman. Além disso, ao prever a reação do ouvinte, na busca de um acordo prévio para as suas ideias, Platão está pensando na recepção de um auditório universal, tal como o próprio Perelman sugere, ao narrar a necessidade de se buscar um acordo prévio com o auditório. ${ }^{49}$

\footnotetext{
${ }^{46}$ Cf. PERELMAN, 1970a, p.77-83. apud PERELMAN, 1989, p.52.

${ }^{47}$ GOBLOT, 1927, p. 16-17. apud. PERELMAN ; OLBRECHTS-TYTECA, 1999, p.40.

${ }^{48}$ PERELMAN, 1997, p. 48-49.

${ }^{49}$ PERELMAN; OLBRECHTS-TYTECA, 1999, p.75.
} 
Além disso, Perelman parece estar equivocado porque não cogita a construção de uma "personalidade virtual", que corresponde àquela que se torna presente onde, de fato, não há um elemento instalado, visto que é possível construir um diálogo a partir de certos dados concernentes a uma personalidade que não possui assento no mundo real, empiricamente dado. Isso, aliás, não consiste em qualquer novidade: (1) Quando Goethe ${ }^{50}$ ou mesmo Sheakspeare ${ }^{51}$ constroem os seus diálogos para Fausto ou Hamlet, respectivamente, estão elaborando um tipo de "personalidade virtual" que Perelman parece desprezar (...) (2) Em Filosofia, além de Platão, também Voltaire constrói personagens que descrevem criticamente traços da personalidade de certos grupos. Assim, um Bom Brâmane assemelha-se, em muitos aspectos, a elementos que creem cegamente nos entes metafísicos presentes na natureza.

Não se trata de um procedimento do tipo causa-efeito, donde decorreria do questionamento $\mathrm{X}$ uma resposta $\mathrm{Y}$, para quaisquer casos em que $\mathrm{X}$ se aplique, porque os elementos, racionais e razoáveis pensarão da mesma maneira. Pelo contrário, acredita-se que dado a ocorrência do questionamento $\mathrm{X}$, é provável que Y seja a resposta, considerando-se as características do elemento ao qual tal pergunta estará sendo encaminhada, o contexto no qual ela se inserirá, a pressão que será impressa no mesmo, o tempo e a atenção que serão empregadas para isso, o rigor que se espera da resposta, e a resposta que se espera do questionamento, dentre outros fatores. Também esses dados correspondem ao que empresas de publicidade desenvolvem na produção das suas campanhas, visando atingir o seu público. O efeito psicológico dos argumentos não precisa ser testado no mundo empírico, real e concreto. Com base em informações acerca do seu público alvo, que nesse caso em específico é o seu interlocutor, podem-se construir diálogos hipotéticos baseados na estrutura virtual de uma cena comum do cotidiano. Assim, por "construções virtuais", que também podem ser chamadas de "simulações de diálogo", pode-se conviver com a interpretação de Goblot sem que, para isso, se tenha de criar uma ideia de essencialismo tal como prega a compreensão desenvolvida por Perelman.

Perelman, posicionando-se como um crítico qualificado do pensamento moderno, promove um alinhamento da sua teoria com as ideias remanescentes dos pensadores clássicos

\footnotetext{
${ }^{50}$ Cf. GOETHE, 1976.

${ }^{51}$ Cf. SHAKESPEARE, 1976.
} 
da antiguidade. Embora, em um primeiro momento, condene o procedimento de tornar a Dialética uma Lógica, posteriormente ${ }^{52}$, ele mesmo defende a ideia de que a Lógica não pode ser engessada e estática como a lógica formal à qual aquela ficou seriamente reduzida, motivo pelo qual ela precisa ser revista e empreendida sob a iluminação de uma Dialética e ou de uma Retórica. In verbis:

(...) O método dialético, correlativo, em nossa mente, de um pensamento dialogado, se transformaria num sistema dialético, monolítico, no qual a partir de teses iniciais, as consequências se desenvolveriam de forma automática que não deixaria nenhum espaço à personalidade não só de quem responde, mas também do próprio dialético. Dialética e Lógica analítica coincidiriam. O procedimento dialético não seria tão coercivo quanto a demonstração formal e, para consegui-lo, deveria beneficiar-se da mesma univocidade dos termos aos quais se aplica e do mesmo caráter indiscutível de suas regras operatórias. Tornando-se uma Lógica, a Dialética se transforma em um sistema de encadeamentos necessários, mas à custa do abandono de qualquer conformidade com um diálogo real, cujo desenrolar é condicionado tanto à personalidade dos interlocutores quanto às intenções que os animam. ${ }^{53}$

Ainda que Perelman omita, é indubitável que as palavras de Goblot fornecem o alicerce sobre o qual se edificam algumas noções capitais do pensamento perelmaniano, como a noção de "deliberação consigo mesmo" e, sobretudo, a noção de dialética que serve de pilar para a reconstrução da Retórica na contemporaneidade. ${ }^{54} \mathrm{~A}$ ideia de Perelman acerca da Retórica está em conformidade com o pensamento de Platão acerca da Dialética. Daí porque insistimos em aproximar a Nova Retórica perelmaniana de uma Nova Dialética. O método dialético, pelo menos antes de Platão, era essencialmente dependente da presença de, no mínimo, dois interlocutores in locu expressando oralmente os seus assentimentos e discordâncias sobre aquilo em torno do que se discorria. Se Platão transpõe o diálogo para o plano da linguagem escrita, Perelman faz o mesmo com a Retórica, atraindo-a para um campo alheio à sua atuação original, ou seja, para outros campos da expressão linguística, em especial, a escrita. Do mesmo modo, se Platão acredita que um único indivíduo e sua obra podem exercer a dialética pela criação de um diálogo virtual, entre dois personagens imaginários que travam um debate sobre um assunto específico, Perelman vê nessa aplicação da noção de Dialética uma utilização de ordem prática, uma vez que ele próprio enuncia algo semelhante ao tratar da deliberação consigo mesmo, considerada uma modalidade de auditório em que se aplicam regras destinadas à condução do próprio pensamento. Que se pretende dizer com isso? Objetiva-se exprimir que o indivíduo que delibera consigo mesmo elabora as perguntas e, em seguida, formula com o maior rigor

\footnotetext{
52 PERELMAN, 1998, p. 5-6.

${ }^{53}$ PERELMAN, 1997, p.49

${ }^{54}$ A esse respeito publiquei As múltiplas faces de um único termo: Dialética (OLIVEIRA, 2000, p. 21-36).
} 
possível, as respostas mais adequadas para aquele questionamento, levando em conta as possíveis objeções que poderiam ser concedidas às suas respostas. Neste caso, o indivíduo aprimora a sua habilidade argumentativa considerando antecipadamente a possibilidade de suas afirmações serem refutadas. Não parte do pressuposto que a sua concepção é perfeita e acabada, impossível de ser refutada; não incorpora falsas pretensões ou suposições absurdas como acreditar na possibilidade de esgotar os problemas da Filosofia. Longe de imaginar acabar com a Filosofia, essa concepção a trata como algo incessantemente em construção, mutável, inconsistente e surpreendentemente vigorosa, por sua capacidade de autoconstrução, e por ser essencialmente controversa e aberta a novas possibilidades de compreensão.

No que se refere à deliberação consigo mesmo e ao crédito que pode ser concedido a esta modalidade de argumentação, vale destacar que a sua compreensão se torna mais simples quando se resgata o pensamento platônico como exemplo. Quando Platão desenvolve um diálogo filosófico empreendendo perguntas e simulando respostas prováveis para aquele tipo de questionamento, está imaginando como pessoas racionais, esclarecidas e capazes poderiam responder, de uma forma (mais ou menos) elaborada conforme o seu nível de formação e a importância dedicada ao tema em discussão. Quanto mais óbvio possa parecer um questionamento, menor será a intensidade de atenção dedicada ao mesmo e, por conseguinte, maior será a rapidez com a qual ele será respondido. Essa atenção reduzida decorre do excesso de confiança do indivíduo inquirido, que crê cegamente na solidez inabalável dos seus conhecimentos e, por extensão, na sua experiência. Esse tipo de comportamento é absolutamente antifilosófico, porque mascara as outras possibilidades de interpretação de um mesmo evento. A noção de racional, neste caso, aproxima-se da concepção de razoável encontrada no pensamento de Aristóteles ${ }^{55}$, resgatada por Perelman e seguida, nos últimos anos, por outros pensadores a exemplo de Recaséns Siches. A noção platônica, resgatada por Perelman, acerca da possibilidade de uma Dialética que opera num único indivíduo recorre à ideia sustentada no ideal de racionalidade específica segundo o qual existe uma capacidade (predisposição) igual nas pessoas para pensar de maneira semelhante sobre um mesmo evento.

O diálogo torna-se efetivamente dialético quando, para além de ter coerência interna em seus discursos, os interlocutores procuram chegar a um acordo no tocante às opiniões que

\footnotetext{
${ }^{55}$ São razoáveis as "opiniões geralmente aceitas" tal como se vê nos Tópicos: "são, por outro lado, opiniões geralmente aceitas aquelas que todo mundo admite, ou a maioria das pessoas, ou os filósofos --em outras palavras: todos, ou a maioria, ou os mais notáveis e eminentes" (ARISTÓTELES, 2007, p.234, 100b 21). A esse respeito pode ser útil a leitura do texto intitulado A Quadratura do Círculo na Física de Aristóteles (OLIVEIRA, 2002, p. 45-66).
} 
consideram mais sólidas. É a partir desse estágio que o diálogo passa a ter um interesse filosófico construtivo. Se Platão utiliza a busca da verdade como força motriz para a utilização do método dialético, Aristóteles usa o método dialético estruturando a sua argumentação a partir de proposições geralmente aceitas. Assim, a distinção entre o método analítico e o dialético perpassa a questão estrutural de ambos, visto que o primeiro deles toma como ponto de partida as proposições necessárias que conduzem a conclusões evidentes, enquanto o segundo se orienta a partir de proposições geralmente aceitas para chegar às conclusões que mais estejam em conformidade com a opinião comum (dos mais sábios ou dos mais esclarecidos).

A função do filósofo e, por conseguinte, do discurso que lhe caracteriza, na perspectiva perelmaniana, representa um afastamento de postulações epistêmicas extremistas como o realismo e o idealismo, cuja derivação criticista concede origem ao conhecimento a priori e a posteriori, respectivamente. Perelman foge da unilateralidade que caracteriza cada um desses posicionamentos, procurando uma síntese doutrinária de caráter agregador. Nesse sentido, seu entendimento segue uma metodologia dialética consistente, que engloba elementos opostos apresentados pelos discursos, não apenas por meio de uma justaposição de conteúdo, mas por intermédio de incorporação de elementos que, embora sejam opostos, se complementam na busca de um entendimento comum, fundamentado em um modelo de racionalidade argumentativa.

\section{REFERÊNCIAS BIBLIOGRÁFICAS}

ARISTÓTELES. Tópicos. Lisboa: Imprensa Nacional - Casa da Moeda, 2007.

BURGOS, Gerardo Mora. Racionalidad y tipos de racionalidad. Revista de Filosofía de la Universidad de la Costa Rica. XLI. n.103. Enero-Junio, 2003, p. 93-100.

DESCARTES. Discurso do Método. Trad.: J.Guinsburg e Bento Prado Jr. São Paulo: Abril Cultural, 1979.

DESCARTES. Regras para a direção do espírito. Trad.: João Gama. Lisboa: Edições 70, 1989.

DESCARTES. Euvres. T. XI: Règles pour la direction de l'espirit. Paris, 1826.

ENGISH, Karl. Direito dos juristas. Conceitos jurídicos indeterminados, conceitos normativos, poder discricionário. Introdução ao Pensamento Jurídico. Trad.: J. Baptista Machado. Lisboa: Fundação Calouste Gulbenkian, 1988.

FERES, Marcos Vinício Chein; ALVES, Marco Antônio Sousa. Racionalidade ou razoabilidade? Uma questão posta para a dogmática. Revista da Faculdade de Direito da UFMG [recurso eletrônico], Belo Horizonte, n. 39, p. 285-315, jan./jun. 2001. Disponível em: <http://dspace/xmlui/bitstream/item/12822/1133.pdf?sequence=1>. Acesso em: 6 fev. 2021 .

GOETHE, Johann Wolfgang. Fausto. São Paulo: Abril Cultural, 1976. 
HARGER, Marcelo. A discricionariedade e os conceitos jurídicos indeterminados. Revista dos Tribunais: São Paulo, v. 87, n. 756, out. 1998, p.11-36.

HUME, David. Tratado da Natureza Humana. São Paulo: UNESP, 2001.

LARENZ, Karl. Derecho justo: fundamentos de ética jurídica. Trad.: Luís Díez-Picazo. Madri: Civitas, 1985.

MACCORMICK, Neil. On Reasonableness. PERELMAN, Chaïm ; ELST, R. Vander. Les Notions a Contenu variable en Droit. Bruxelles: Bruylant, 1984.

MORÃO, Arthur. Breve notícia. In: DESCARTES. Regras para a direção do espírito. Lisboa: Edições 70, 1989.

OLIVEIRA, Eduardo Chagas. A Quadratura do Círculo na Física de Aristóteles. Ideação, n.10, Feira de Santana: UEFS, (julho) 2002. p. 45-66.

OLIVEIRA, Eduardo Chagas. As múltiplas faces de um único termo: Dialética. Ideação, n.6, Feira de Santana: UEFS, (julho) 2000. p. 21-36.

PERELMAN, Chaïm; OLBRECHTS-TYTECA, Lucie. Tratado da Argumentação: a Nova Retórica. São Paulo: Martins Fontes, 1999.

PERELMAN, Chaïm. Ética e direito. São Paulo: Martins Fontes, 1996.

PERELMAN, Chaïm. Le raisonnable et le déraisonnable en droit. Archives de philosophie du droit, t.23, 1978, p. 35-42.

PERELMAN, Chaïm; OLBRECHTS-TYTECA, Lucie. Logique et Rhétorique. Revue philosophique de la France et de l'étranger. Paris : janvier-mar, 1950.

PERELMAN, Chaïm. Logique et Rhetorique. Revue philosophique de la France et de l'étranger. Paris, Janvier-Mars, 1950.

PERELMAN, Chaïm. Une théorie philosophique de l'argumentation. Le Champ de l'argumentation. Bruxelles: Presses Universitaires de Bruxelles, 1970. (Travaux de la Faculté de Philosophie et lettres, Tome XLIII).

PERELMAN, Chaïm. Retóricas. São Paulo: Martins Fontes, 1997.

PLATÃO. A República. Lisboa: Fundação Calouste Gulbenkian, 1980.

SEARLE, John R. Racionalidade e Realismo: o que está em causa? Disputatio 1 (7), 1999, p.227.

SHAKESPEARE, William. Hamlet. São Paulo: Abril Cultural, 1976.

SICHES, Luis Recaséns. Experiência jurídica, naturaleza de la cosa y lógica "razonada". México: Dianoia, 1971.

SIDGWICK, Henry. The Methods of Ethics. London: Macmillan, 1907.

TOULMIN, Stephen Edelston. Return to reason. Cambridge: Harvard University Press, 2001

VON WRIGHT, Georg Henrik. Deontic Logic. Mind, LX, no. 237, 1951, p.1-15

WINCH, Peter. The Universalizability of Moral Judgements. The Monist. V. 49, Issue 2, 1 April 1965, p. 196-214. Disponível em: <https://doi.org/10.5840/monist196549214>. Acesso em: 6 fev. 2021. 